\title{
Serviço Social e Consultoria Empresarial
}

Sarah Tavares Cortês'

BOTÃO, Márcia. Serviço Social e Consultoria Empresarial. Rio de Janeiro: Gramma, 2020. 216p.

Artigo recebido em janeiro de 2021

Artigo aprovado em fevereiro de 2021

Recém lançado, o livro "Serviço social e Consultoria Empresarial" é uma obra produzida a partir da pesquisa de doutorado da assistente social e professora Márcia Botão. A autora, é doutora em Serviço Social pela Universidade do Estado do Rio de Janeiro (UERJ), com vínculo docente na Pontifícia Universidade do Rio de Janeiro (PUC-Rio). Desenvolve suas pesquisas na linha "Trabalho, Políticas Públicas e Serviço Social", principalmente acerca do trabalho de assistentes sociais, com ênfase na área de empresas.

A obra foi prefaciada pela professora Lúcia Freire, que já no início indica ao leitor chaves de análise que a obra traz e enfatiza a importância para o Serviço Social. Em suas palavras, escreve: "Este livro, portanto, coloca a nu os limites, tanto da 'fábrica mínima', como da 'consultoria empresarial' nas condições exíguas para o exercício ético-político do Serviço Social."

O livro conta também com as participações das professoras Inez Stampa e Valéria Bastos, nos elementos extratextuais. A profa. Inez Stampa escreveu a orelha do livro, dando destaque à construção de "um aporte valioso para a compreensão do trabalho de assistentes sociais no contexto de acirramento da crise do capital e aprofundamento da reestruturação produtiva". A profa. Valéria Bastos escreveu a contracapa, apresentando ao leitor a centralidade da análise presente na produção teórica: “formas 
perversas desenvolvidas a partir da crise do capital e da reestruturação produtiva, em relação à prestação de serviços por assistentes sociais, entre outros, da área de recursos humanos, não efetivos das instituições, por meio de contratações terceirizadas que intermedeiam esses serviços, denominadas 'consultorias"'; oferecendo também, comentários positivos acerca da importância que essa produção tem, "sobretudo em relação aos desafıos a serem vencidos no século XXI".

As participações supracitadas atestam as contribuições fundamentais que essa obra oferece ao Serviço Social, com um caráter de ineditismo. Uma vez que a temática das chamadas "consultorias empresariais" foi tratada como objeto de investigação, pela primeira vez, na ocasião da pesquisa de mestrado da autora, em 2010, sendo aprimorada no curso de doutorado, embora outros autores tenham investido em sínteses analíticas sobre o tema. Posteriormente, outras produções foram elaboradas em Programas de pós-graduação em Serviço Social, sendo necessário maior investimento nesse tema, uma vez que os modos de precarização da força de trabalho tendem a se manter e até mesmo ser aprofundados de várias formas. Uma delas está na intensificação do teletrabalho, já presente em algumas “consultorias” pesquisadas.

O livro é resultado de um acúmulo de experiências da autora, no âmbito acadêmico, como mencionado, mas também se relaciona com a bagagem que traz do trabalho na área de empresas. Pode-se dizer, que essa pesquisa tem por base o movimento real das indústrias multinacionais e de empresas de outros ramos, como o de serviços de telecomunicações e a sua relação com pequenas empresas e profissionais prestadores(as) de serviços. Desenvolve suas análises a partir de interlocuções com as falas de profissionais, isso significa que a autora se debruça sobre a realidade do trabalho de assistentes sociais, sem perder de vista a densidade teórico-analítica necessária para revelar a essência da dinâmica que se apresenta na realidade societária atual, trazendo como recorte o trabalho do serviço social nas chamadas “consultorias empresariais". 
Nas palavras da autora (BOTÃO, 2020, p.17/18):

o livro tem como objetivo central verificar os caminhos que a profissão vem trilhando por meio das denominadas "consultorias" e identificar se elas apontam para a consolidação do projeto ético-político profissional pela categoria ou se estão contribuindo para afastá-la desse projeto, diante das condições de tralho e de outros elementos no espaço sócio-ocupacional da "consultoria empresarial".

Cabe aqui, uma explicação conceitual que precede a compreensão da discussão desenvolvida no decorrer do livro. A autora parte da concepção que consultoria compreende um nível de atividade que objetiva "qualifıcação do trabalho desempenhado com vistas à ampliação dos direitos dos trabalhadores" (BOTÃO, 2020, p.17). É utilizado o marcador das aspas para diferir, do sentido original, as "consultorias empresariais", que "têm se configurado em expressão do trabalho precário no contexto de crise do capital e de reestruturação produtiva" (BOTÃO, 2020, p.17).

Nesse sentido, o objeto sobre o qual a obra se desenvolve

consiste na análise das denominadas "consultorias empresariais" que contratam os serviços dos assistentes sociais sob a denominação de "consultores", contrapostas a seu sentido próprio, como mais uma expressão da precarização do trabalho no contexto de crise do capital e de suas formas de reestruturação. Nossa hipótese inicial confirmada consiste em apontar que essas "consultorias" ocultam a precarização dos vínculos de trabalho de profissionais qualificados de nivel superior, entre eles as assistentes sociais, integrantes da classe trabalhadora que, como tal, sofrem as injunções pelo capital das estratégias neoliberais de superação de sua crise, incidindo nas condições e na qualidade do trabalho profissional. As profissionais inseridas nesses espaços sócio-ocupacionais, apesar de terem, em sua maioria, uma análise crítica sobre a sociedade e o local de trabalho, deparam-se com poucas possibilidades de um exercício crítico e propositivo, tendo sua autonomia relativa reduzida. 
As análises estão apoiadas em pesquisas de natureza teórica e empírica, sobre duas modalidades de consultoria: as empresas especializadas em Programa de Assistência ao Empregado (PAE) e as empresas especializadas em serviço social. No total foram nove profissionais entrevistados(as) vinculados(as) formal ou informalmente à quatro empresas (uma especializada no PAE, uma especializada em serviço social e duas empresas contratantes do PAE). As empresas estão sediadas nos estados do Rio de Janeiro e São Paulo, com abrangência nacional e uma contratante com abrangência internacional.

Os resultados são analisados com base na teoria social crítica marxista e apresentados no decorrer do livro, que, por sua vez, estrutura-se em introdução, três capítulos e considerações finais, além do prefácio e referências.

A introdução é um convite ao leitor. De início, já é apresentado o ponto de partida do entendimento acerca da "consultoria empresarial" e o objetivo central do livro, conforme exposto anteriormente. Desenvolve-se um pouco da trajetória profissional da autora e sua relação com o objeto, o que leva a compreender a realidade que deu origem aos estudos empreendidos, envolvendo o leitor na trama da temática proposta no livro. Por fim, a autora situa ainda o método, o objeto, aspectos metodológicos da pesquisa e alguns conceitos e categorias chaves, relacionados às particularidades que seu texto pretende explorar.

O primeiro capítulo, intitulado "A crise do capital e seus impactos na organização, na gestão e no consumo da força de trabalho", está dividido em três subitens: "A crise contemporânea do capital, suas contradições e consequências para a classe trabalhadora"; "Trabalho, classes sociais e o assistente social como classe trabalhadora"; "Rebatimentos da crise do capital na classe trabalhadora: os padrões de gestão, a situação brasileira e a apropriação das consultorias pelo capital".

Nesse capítulo, a autora apresenta uma primeira síntese sobre as transformações do trabalho ocorridas a partir da década de 1970 nos países europeus e 1990 no Brasil. Portanto, vai tratar acerca do debate 
sobre a crise do capital, bem como suas repercussões na organização e nas relações de trabalho. Analisa o processo de reestruturação produtiva, os impactos para a classe trabalhadora, buscando as conexões com o serviço social - como profissão que integra essa classe - especialmente na forma das "consultorias", também para os próprios usuários demandantes dos serviços.

Dialoga com autores que desenvolvem estudos sobre a categoria de crise e reestruturação produtiva como Mandel, Harvey, Mészáros, Antunes, Fontes, ademais de autores com formação em Serviço Social como Mota, Netto e Braz, Durigueto e Montaño.

O segundo capítulo, chamado "O avanço do conservadorismo no Serviço Social no século XXI", vai adentrar mais o significado do termo consultoria e as suas diferentes concepções. Esse debate está sistematizado em três momentos: "O serviço social no início do século XXI e o avanço do conservadorismo"; "Consultorias: diferentes interpretações, objetivos e vinculações institucionais"; "Consultoria social nas empresas: entre a inovação e a precarização silenciosa no serviço social".

Ao longo do capítulo Botão (2020) qualifica o sentido original de consultoria, apoiando-se em autores como lamamoto, Freire, Mota e Amaral, Cesar, Matos, Vasconcelos. Ao mesmo tempo, desmistifica o que tem se chamado de "consultoria empresarial", considerando a apropriação dessa atividade nos processos de focalização e superespecialização desencadeados pela reestruturação produtiva, com objetivo da precarização do trabalho, justificando a terceirização/quarteirização da oferta de serviços de atendimento à saúde e assistência ao trabalhador. Essa realidade não é homogênea, há trabalhos de consultoria e assessoria de qualidade em empresas ou em outras áreas, sendo importante compreender as diferenças dessas consultorias.

A autora analisa que essa precarização silenciosa, mascarada de inovação através da "consultoria empresarial", tem consequências "para o serviço social e para os usuários dos seus serviços, pois uma contratação precarizada oculta no processo de reestruturação produ- 
tiva torna mais difícil o trabalho profissional, assim como as formas de resistência às perdas de direitos trabalhistas" (p.85).

O último capítulo, “Configurações de duas modalidades de "consultorias empresariais'" problematiza duas modalidades de consultoria, que predomina certa forma de prestação de serviço: os Programas de Assistência ao Empregado (PAEs) e as consultorias especializadas em serviço social.

Os PAEs são serviços, como pacote de atendimento, vendido às empresas para que o(a) trabalhador(a) seja atendido(a) por profissionais via uma linha de call center, atuando em quatro áreas principais: psicológico, social, financeiro e jurídico. Estes são apresentados nos itens 3.1 "Programas de Assistência ao Empregado (PAEs): características de suas formas de precarização, terceirização e informalização do serviço social ocultadas sob a denominação de "consultorias'” e 3.2 "Impactos dos serviços de assistência ao empregado (PAE) para os assistentes sociais, os trabalhadores e os empregadores". Essa modalidade privilegia o trabalho de assistentes sociais remotamente, assim como as contratações por serviços prestados.

No decorrer do capítulo, a autora explica a origem, formas de contratação, abrangência e as condições de trabalho dos(as) profissionais que desenvolvem os atendimentos dos PAEs. Em linhas gerais, trata-se de um atendimento focal, com consequência em uma hiperindividualização que aparta os problemas da relação do trabalho, podendo ocasionar questões físicas e mentais severas para o trabalhador, pois esse isolamento e individualização do problema, pode levar ao sentimento de angústia, depressão, incompetência, incapacidade, ademais da descaracterização dos direitos de assistência ao trabalhador como coletivos.

As "consultorias" especializadas em serviço social, por sua vez, "são aquelas que se propõem terceirizar principalmente o serviço social" (p.190). Assistentes sociais, também psicólogos, são contratados pelas empresas de "consultoria", todavia desenvolve seu trabalho em outra empresa (médio/grande porte). Essas são problematizadas no item 3.3 
"Consultoria especializada em serviço social: precarização e terceirização dentro da empresa, a ênfase no duplo controle produtivista do assistente social e a redução da autonomia relativa". Observa-se aqui a marca da terceirização, fragmentação de programas/projetos e dupla subordinação pela intermediação de empresas com outras empresas, cujas propostas de intervenções são transformadas em produtos a serem negociados entre empresas, não mais entre patrão e empregado.

O livro se refere a uma análise da organização social do trabalho, especialmente na forma das "consultorias empresariais"; não se trata de uma crítica aos trabalhadores de consultoria. Muito ao contrário, busca-se ao longo da exposição um diálogo com os(as) profissionais da área de empresa, em especial assistentes sociais, desvelando a partir das suas falas realidades e condições desses(as) trabalhadores(as), revelando-se tendências à terceirização/quarteirização, ao teletrabaIho, ao aprofundamento dos processos de alienação e desvalorização, não apenas para o serviço social, como para outras profissões. Tudo isso muito bem disfarçado pelo status da inovação, do empreendedorismo e da aparente autonomia profissional.

"Serviço Social e consultoria empresarial" desenvolve, portanto, um conjunto de argumentos para desmistificar o que tem se chamado de "consultoria empresarial", conceito que apresenta uma racionalidade sofisticada de redução de custo da força de trabalho, o qual incide na precarização da vida de forma subjetiva e objetiva. Esse tema é necessário para o Serviço Social, também possui um caráter inédito, uma vez que é o primeiro livro que revela as tendências de apropriação da qualidade das consultorias para justificar a precarização do trabalho.

A obra tem fundamentações teóricas consistentes e está escrita em linguagem dialógica, clara e de fácil entendimento para o leitor. Recomenda-se a sua leitura, especialmente para assistentes sociais, professores(as) e estudantes de serviço social, também de áreas afins. Considera-se que a pesquisa que a autora apresenta é importante ferramenta para entender a realidade e os processos de organização do 
trabalho que a profissão se insere na área de empresa, mas não se resume a esse espaço sócio-ocupacional, pois a lógica da gestão empresarial afeta as demais áreas de atuação profissional seja no setor público ou no setor privado. Em síntese, o debate proposto reafirma o direcionamento ético-político hegemônico da profissão de defesa da classe trabalhadora, mesmo nos espaços mais adversos de trabalho.

\section{Nota}

1 Doutoranda no Programa de Pós-graduação em Serviço Social da Pontifícia Universidade Católica do Rio de Janeiro (PUC-Rio). Mestre pelo Programa de Pós- graduação em Serviço Social da Universidade Federal do Rio Grande do Norte (UFRN). Assistente Social servidora do Instituto Federal de Educação, Ciência e Tecnologia da Paraíba (IFPB). E-mail: sarahtcortes@gmail.com. № https://orcid. org/0000-0001-7944-6280 